\title{
OBTAINING OF UFG STRUCTURE OF ZR-1\% NB ALLOY BY RADIAL-SHEAR ROLLING
}

\author{
${ }^{1}$ Alexandr ARBUZ, ${ }^{2}$ Anna KAWALEK, ${ }^{2}$ Kirill OZHMEGOV, ${ }^{1}$ Nurgul DANIYEVA, ${ }^{3}$ Evgeniy PANIN \\ 1Nazarbayev University, Nur-Sultan, Kazakhstan, zubra kz@mail.ru, nurqul.daniyeva@nu.edu.kz \\ ${ }^{2}$ Częstochowa University of Technology, Częstochowa, Poland, EU, \\ kawalek.anna@wip.pcz.pl,kvozhmegov@wp.pl \\ 3Karaganda State Industrial University, Temirtau, Kazakhstan, cooper802@mail.ru
}

https://doi.org/10.37904/metal.2020.3485

\begin{abstract}
An overview of the prospects for the development of nuclear technologies and the conclusion of the relevant requirements for advanced structural materials, their classification and features were described. In order to obtain a bar with a modified radiation-resistant outer layer, an experiment on radial-shear rolling of the $\mathrm{Zr}$ - $1 \%$ $\mathrm{Nb}$ alloy in conditions favorable for the UFG structure formation was conducted. In the process of radial-shear rolling of round bars along the route $37 \mathrm{~mm} \rightarrow 20 \mathrm{~mm}$ in diameters with a total deformation of $\varepsilon \approx 70 \%$, a microstructure of submicron size was obtained. The nature of the microstructure is equiaxed with mainly high-angle boundaries and large crystallographic misorientation of the grains that is the most promising from the point of view of radiation resistance.
\end{abstract}

Keywords: UFG, severe plastic deformation, radial-shear rolling, TEM, zirconium

\section{INTRODUCTION}

Zirconium is the most popular material in the nuclear power industry. Alloys based on it are used for the production of the most important part of nuclear reactors - for the material of shells (nuclear fuel cladding tubes) and plugs (end plug) of fuel elements of thermal neutron reactors (PWR, WWER). These tubes contain tablets of nuclear fuel and separate it from the inner space of the reactor. Therefore, their properties are subject to exceptional requirements [1].

The main concept of creating a new generation of nuclear reactors is to increase their safety level, increase their service life and power [1-3]. The development of nuclear technology is associated with a gradual increase in operating temperatures and pressures in the reactor core [2]. Also, the problem of creating small nuclear reactors with particularly long-term autonomous operation for stable energy supply in extreme conditions without maintenance is relevant [4]. At the same time, the main problem with increasing power and durability, and, consequently, with safety, is the degradation of structural materials under prolonged exposure to ionizing radiation in an aggressive environment and high temperatures [5].

The main aim of this work is an experimental investigation of radial-shear rolling process of $\mathrm{Zr}-1 \% \mathrm{Nb}$ alloy for possible obtaining of ultrafine-grained structure.

\section{FEATURES OF ULTRAFINE-GRAINED AND NANOSTRUCTURED MATERIALS AND METHODS OF THEIR PRODUCTION}

One of the ways to increase the level of mechanical properties and radiation resistance is the use of ultrafinegrained (UFG) and nanostructured materials (NS) [6]. All industrially used metal materials have a coarsegrained structure with a grain size of about 20-80 microns or more. The UFG state, with a grain size of less than $1000 \mathrm{~nm}$, significantly changes the mechanical and physical properties of the material. The strength 
increases several times while maintaining a sufficiently high level of plasticity, which is very beneficial for structural materials. These materials, their properties and features of production are described in detail in the works of R.Z. Valiev, T. Langdon, and others [6-9].

Such materials, due to the small grain size, contain a large number of grain boundaries in the structure, which play a decisive role in the formation of their physical and mechanical properties. Ideas about non-equilibrium grain boundaries are based on studies of the interaction of lattice dislocations and grain boundaries, in the result of which the introduced grain-boundary dislocations (GBD) are formed. They form the special state of grain boundaries that allows to obtain increased physical and mechanical properties of materials. Such structures are characterized by a high level of strength and a sufficient level of plastic characteristics immediately after production. Thus, the nature and state of the grain boundaries have a decisive influence on the properties of the material.

The physical mechanism for increasing radiation resistance also consists in the fact that UFG and nanostructured metals have a much larger number of grains per unit volume, and therefore a relatively large proportion of intergranular boundaries in the volume of the body. In the case of a radiation defect, due to the proximity of grain boundaries, the defect quickly reaches the grain boundaries that serve as the surface of the drain and disappears. In particular, a decrease in the proportion of amorphization, radiation hardening and swelling was recorded for nanostructured alloys obtained by equal-channel angular pressing $[10,11]$ - the most common method for obtaining UFG structures. The study of radiation resistance of this class of materials is most actively conducted in the nuclear centers of the United States [12], France [13], Japan [14] and other countries $[15,16]$.

Obtaining the UFG and nanostructured state is possible either by sintering ultrafine powders, or by severe plastic deformation method (SPD). The use of SPD eliminates the presence of residual porosity characteristic of sintering powders, but has more stringent requirements for the process conditions: 1 ) achievement of high degrees of deformation for grain grinding $(\varepsilon>6-8) ; 2)$ formation of high hydrostatic pressure preventing sample destruction and annihilation of crystal lattice defects (1 GPA and higher); 3 ) deformation at temperatures of about 0.4 of the melting point and below to exclude the phase transition $\alpha \rightarrow \alpha+\beta$ [17] (for zirconium); 4 ) ensuring turbulence and non-monotonicity of the deformation, contributing to the formation of high-angle intergranular boundaries.

Similar conditions can be obtained by such methods as high-pressure torsion, equal-channel angular pressing, screw extrusion, all-round forging, and some others.

The most popular methods that implement these conditions are equal channel angular pressing in $6-8$ cycles or more (ECAP) [11] and high pressure torsion (HPT), as the evolution of the Bridgman anvil [1,7-8,18-20].

These methods make it possible to obtain ultrafine grain for a number of materials (there are many times confirmed protocols for various materials) and, judging by the ratio of publications, they are most in demand for scientific research. These methods are the main ones in more than $90 \%$ of publications on UFG materials and in all publications on radiation resistance research. However, when convenient for laboratory use, both methods have two major drawbacks: a limitation in the size of the resulting samples and extremely low production technology, which practically exclude their industrial use. These disadvantages can be eliminated by using a radial-shear rolling method, which also allows to obtain a UFG state, but already in long round bars with some features of the structure distribution [18-20]. The development of this method will make it possible to take a step towards the industrial application of products made of radiation-resistant UFG materials. In radial-shear rolling, a stress state scheme close to all-round compression with large shear deformations is implemented in the deformation zone. The scheme of radial-shear rolling and features of metal flow is shown in Figure 1. The main feature of radial-shear rolling is non-monotonicity and turbulence of deformation, as well as differences in the plastic flow and structure of different zones of the workpiece due to the trajectory-speed characteristics of the process [19]. Due to these features of the metal flow, the most intense shear deformations 
are localized in the zone of intersection of the metal sliding lines - the circular cross-section zone characteristic of the three-roll scheme, which is confirmed by the model. In the outer layer, each small trajectory-oriented element is subjected to compression deformation along the radius of the workpiece, compression deformation in the direction of flow (along the helical trajectory), and, accordingly, stretching deformation across the helical trajectory.
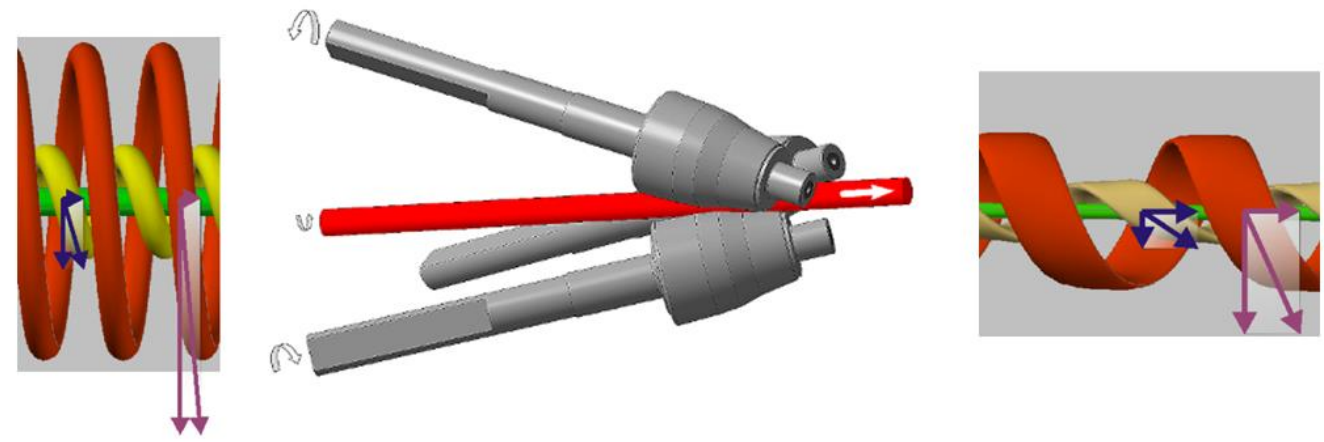

Figure 1 Scheme of radial-shear rolling and features of metal flow in the axial, intermediate and peripheral zones of the workpiece

At the same time, it is important that there is a constant gradient of velocities and flow directions along the radius, which also adds additional shear elements to the overall complex picture of the stress-strain state. Elements of the metal structure subjected to an expanding flow with a two-way precipitation (along the trajectory and along the radius) take the form of isotropic isolated particles of high dispersion [19].

The speed of particles in the axial fiber and its length, as well as in longitudinal rolling, increases in proportion to the extraction coefficient. The cross section of the central current flow tubes decreases. The metal structure processing acts as a type of longitudinal rolling in calibers with multi-sided compression or pressing. Elements of the structural structure are stretched and thinned with the formation of a characteristic structural band frequency. These features are described and illustrated in detail in the works of S.P. Galkin [19]. Recently, a significant change in the structure of conventional steels [20], stainless steels [21-23], aluminum-based alloys [24-25] and magnesium [26] has been successfully obtained by radial-shear rolling.

\section{RADIAL-SHEAR ROLLING OF ZR-1\%NB ALLOY BARS}

Based on the works listed above, NUST MISIS has created designs for radial-shear rolling mills that implement severe plastic deformation of a solid round bar. Among them, the RSP 14-40 mill installed at Częstochowa University of Technology. The appearance of the mill is shown in Figure 2. This mill was chosen for conducting experiments to study the effect of cross-screw rolling on the microstructure of zirconium, because the mill is characterized by a wide range, high rigidity of the cage and ease of operation. Previously, using a similar type of mill, an ultrafine structure with equiaxed grains of 300-700 nm on samples of 08X18N10T austenitic stainless steel was obtained, which is also widely used in nuclear power engineering [21-23]. For conformity assessment implemented by the mill scheme of stress-strain state relative to the above parameters optimal for the formation of the UFG structure is necessary to conduct a computer modeling process in a mill of RSP 14-40.

Radial-shear rolling of blanks made of Zr-1\% NB alloy was carried out at the RSP 14-40 mill at Częstochowa University of Technology. The heating temperature was set at $530{ }^{\circ} \mathrm{C}$ based on known studies of the plasticity of this alloy under similar conditions [27]. The initial bar with a diameter of $37 \mathrm{~mm}$ was heated in a preheated muffle furnace for 40 minutes. To control the temperature mode, an infrared thermal imaging camera was used, aimed at the deformation zone. When exposed to compression of $3 \mathrm{~mm}$ rolls, due to the spring of the cage, on the first pass, the final diameter was a millimeter larger than the exposed, so some passes were rolled 2 times. Rolling was carried out at the maximum mechanical and technological conditions of the mill, 
and there were several cases of jamming of the rolls. The rod was quickly removed, placed in the furnace for heating to the initial temperature, which was recorded by a thermal imager, and the rolling was continued in steps of $1.5-3 \mathrm{~mm}$ until the diameter of $20 \mathrm{~mm}$ was reached. This diameter is the technological limit for large rolls installed in the mill. Rolling to smaller diameters requires transshipment and replacement of rolls and cassettes, which takes time. Therefore, rolling to smaller diameters from a single heating is not possible. These results are intermediate. A short-term increase in temperature from 50 to $150{ }^{\circ} \mathrm{C}$ was recorded as a result of the thermal effect of plastic deformation, which, with small absolute compressions, indicates the occurrence of intense shear deformations. The rolled rod was cooled in air, from it, from the central part, a sample was taken in the form of two segments (10 mm and $30 \mathrm{~mm}$ long) to study changes in the microstructure and properties. The remainder was divided into 3 equal parts to further determine the conditions (heat treatment mode, rolling temperature) of radial-shear rolling in a size of $14-15 \mathrm{~mm}$ in diameter. The samples cut from the rolled bar are shown in Figure 2 (on the right).

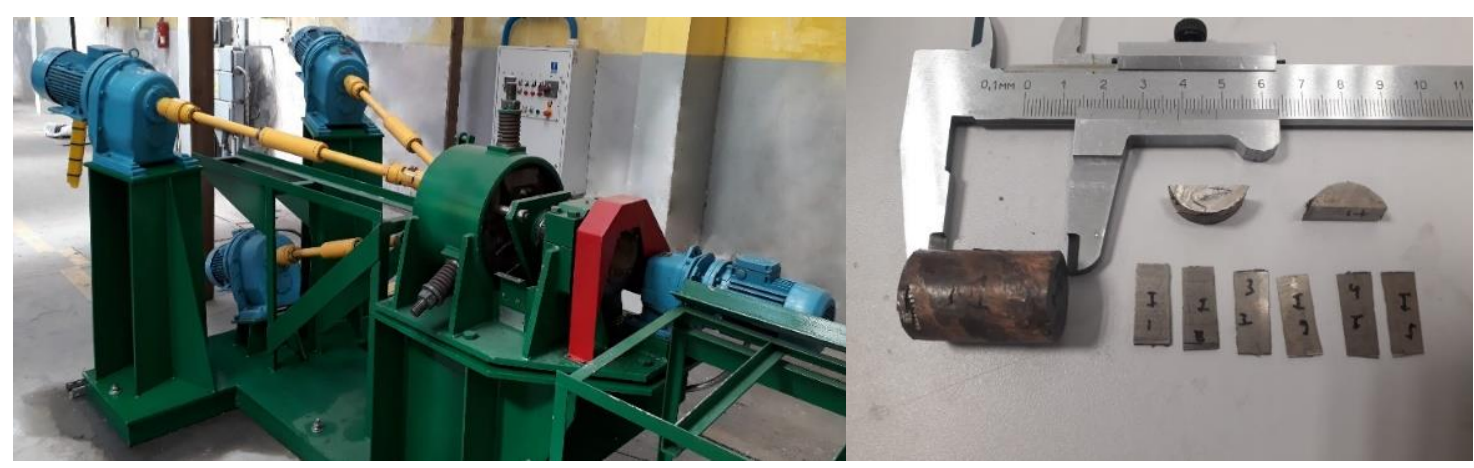

Figure 2 RSP 14-40 radial-shear rolling mill and samples cut from the rolled bar for microstructure study

To study the microstructure using a transmission electron microscope (TEM), a $10 \mathrm{~mm}$ long sample was cut from the central part. Then it was cut in half and several consecutive longitudinal thin $(0.3 \mathrm{~mm})$ sections of the axial region were taken, as shown in Figure 2. Some of the samples were used for testing the sample preparation modes. The cut was carried out on a high-precision cutting machine Brilliant-220 (ATM, Germany) with a water-cooled abrasive wheel at a speed of $500 \mathrm{rpm}$ and a feed of $15 \mu \mathrm{m} / \mathrm{s}$. Samples for transmission microscopy were produced in 2 stages at the TenuPol- 5 facility (Struers, Denmark) in the same A3 electrolyte $(600 \mathrm{ml}$ Methanol, $360 \mathrm{ml}$ Butylcellosolve, $60 \mathrm{ml}$ Perchloric Acid). At the first stage, TEM-object blanks with a diameter of $3 \mathrm{~mm}$ were etched from a solid plate with a thickness of $0.3 \mathrm{~mm}$; at the second stage, these blanks were thinned to form a hole at a voltage of $20 \mathrm{~V}$. In both cases, the region for analysis was the area of longitudinal section at a distance of $2-3 \mathrm{~mm}$ from the edge of the bar. The resulting images are shown in Figure 3.
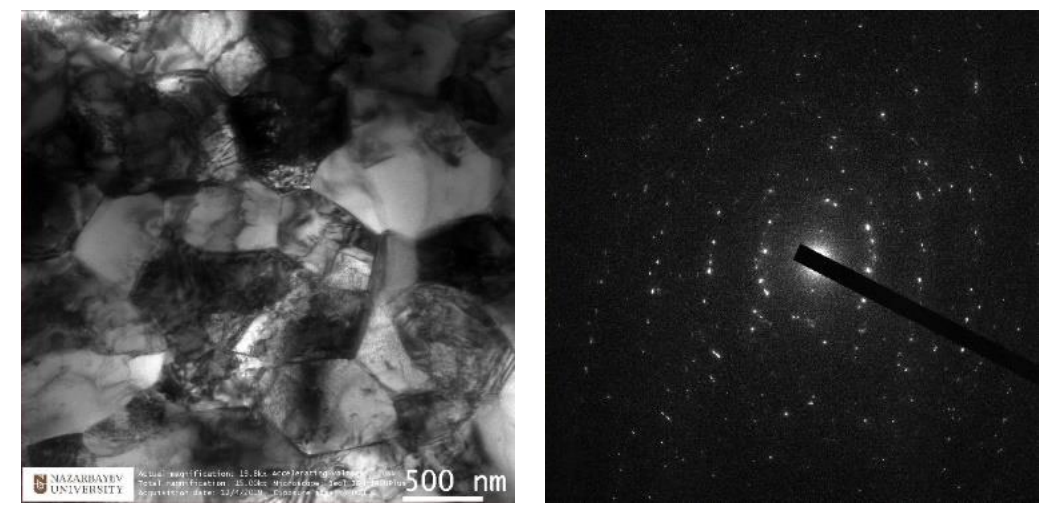

Figure 3 Microstructure of $\mathrm{Zr}-1 \% \mathrm{Nb}$ alloy after radial-shear rolling 
The microstructure was studied using a transmission electron microscope JEM-1400Plus (JEOL, Japan) at an accelerating voltage of $120 \mathrm{kV}$ and an increase of x20000. The resulting images show equiaxially dislocated small grains of submicron size (approximately 500-900 nm). Electron diffraction obtained from these areas also confirmed the absence of a oriented texture. This type of structure is the most optimal for achieving the stated high properties and for further processing by SPD methods in the nanostructured region.

\section{CONCLUSION}

In the process of radial-shear rolling of bars along the route $37 \mathrm{~mm} \rightarrow 20 \mathrm{~mm}$ with a total deformation of $\varepsilon \approx 70 \%$, an equiaxed microstructure of submicron size was obtained. The nature of the microstructure is equiaxed with mainly high-angle boundaries and large crystallographic misorientation of the grains. The resulting microstructure is in good agreement with the research data $[6-7,18-20,24-26]$. The paper notes the applicability of radial-shear rolling in the deformation of bars made of a $\mathrm{Zr}-1 \% \mathrm{Nb}$ zirconium-based alloy to obtain a UFG structure. It is advisable to consider the application of the radial-shear rolling process mainly towards the end of the technological cycle of manufacturing products. Mini radial-shear rolling mills can be used in research work on zirconium alloys as an effective means of warm (0.2-0.4 of the melting point) plastic deformation. In this case, the value of one-time compression is recommended to assign no more than $15 \%$ when rolling bars from the $\mathrm{Zr}-1 \% \mathrm{Nb}$ alloy at the RSP 14-40 mill. The structure obtained in the course of this work will be studied at the DC-60 heavy ion accelerator to conduct a comparative analysis of the behavior of the metal with UFG and other structures. Rolled bars with a diameter of $20 \mathrm{~mm}$ will be used as semi-finished products for the production of nanostructured zirconium in bars with a diameter of $14-15 \mathrm{~mm}$.

\section{ACKNOWLEDGEMENTS}

\section{This research was funded by the Science Committee of the Ministry of Education and Science of the Republic of Kazakhstan (Grant No. AP08052429)}

\section{REFERENCES}

[1] ZINKLE, S.J., BUSBY, J.T. Structural materials for fission \& fusion energy. Materials today. 2009, vol. 12, pp. 1219.

[2] MANSUR, L.K., ROWCLIFFE, A.F., NANSTAD, R.K., ZINKLE, S.J., CORWIN, W.R., STOLLER, R.E. Materials needs for fusion, Generation IV fission reactors and spallation neutron sources - similarities and differences. Journal of Nuclear Materials. 2004, vol. 329-333, pp. 166-172.

[3] ZINKLE, S.J., WAS, G.S. Materials challenges in nuclear energy. Acta Materialia. 2013, vol. 61, pp. 735-758.

[4] INGERSOLL, D.T., COLBERT, C., HOUGHTON, Z., SNUGGERUD, R., GASTON, J.W., EMPEY, M. Can Nuclear Power and Renewables be Friends, NuScale Power, LLC, 2015.

[5] YU, H., DONG, Q., YAO, Z., ZHANG, H.K., KIRK, M.A., DAYMOND, M.R. In-situ study of heavy ion irradiation induced lattice defects and phase instability in $\beta-\mathrm{Zr}$ of a $\mathrm{Zr}-\mathrm{Nb}$ alloy. Journal of Nuclear Materials. 2019, vol. 522, pp. 192-199.

[6] VALIEV, R.Z., ISLAMGALIEV, R.K., ALEXANDROV, I.V. Bulk nanostructured materials from severe plastic deformation. Progress in Materials Science. 2000, vol. 45, no. 2. pp. 103-189.

[7] LANGDON, T.G. The characteristics of grain refinement in materials processed by severe plastic deformation. Reviews on advanced materials science. 2006, vol. 13, pp. 6-14.

[8] XU, C., HORITA, Z., LANGDON, T.G. The evolution of homogeneity in processing by high-pressure torsion. Acta Materialia. 2007, vol. 55, no. 1, pp. 203-212.

[9] TSAY, K., ARBUZ, A., GUSSEYNOV, N., NEMKAEVA, R., OSPANOV, N., KRUPENKIN, I. Refinement of the microstructure of steel by cross rolling. Journal of Chemical Technology and Metallurgy. 2016, vol. 51, no. 4, pp. 385-392. 
[10] SHAMARDIN, V.K., GONCHARENKO, Y.D., BULANOVA, T.M., KARSAKOV, A.A., ALEXANDROV, I.V., ABRAMOVA, M.M. Effect of neutron irradiation on microstructure and properties of austenitic AISI-321 steel subjected to equal-channel angular pressing. Reviews on advanced materials science. 2012, vol. 31, pp. 167173.

[11] SEGAL, V.M. Engineering and commercialization of equal channel angular extrusion (ECAE). Materials Science and Engineering A. 2004, vol. 386, no. 1-2, pp. 269-276.

[12] NITA, N., SCHAEUBLIN, R., VICTORIA, M. Impact of irradiation on the microstructure of nanocrystalline materials. Journal of Nuclear Materials. 2004, vol. 329-333, pp. 953-957

[13] ETIENNE, A., RADIGUET, B., CUNNINGHAM, N. J., ODETTE, G.R., VALIEV, R., PAREIGE, P. Comparison of radiation-induced segregation in ultrafine-grained and conventional 316 austenitic stainless steels. Ultramicroscopy. 2011, vol. 111, pp. 659-663.

[14] MATSUOKA, H., YAMASAKI, T., ZHENG, Y.J., MITAMURA, T., TERASAWA, M., FUKAMI, T. Microstructure and mechanical properties of neutron-irradiated ultra-fine-grained SUS316L stainless steels and Ni-W alloys. Materials Science and Engineering A. 2007, vol. 449-451, pp. 790-793.

[15] WURSTERA, S., PIPPANA, R. Nanostructured metals under irradiation. Scripta Materialia. 2009, vol. 60, pp. 1083-1087.

[16] MAKSIMKIN, O.P., GUSEV, M.N., TSAI, K.V., YAROVCHUK, A.V., RYBALCHENKO, O.V., ENIKEEV, N.A., VALIEV, R. Z., DOBATKIN, S. V. Effect of Neutron Irradiation on the Microstructure and the Mechanical and Corrosion Properties of the Ultrafine Grained Stainless Cr-Ni Steel. Physics of Metals and Metallography. 2015, vol. 116, no. 12, pp. 1270-1278.

[17] DYJA, H., KAWAŁEK, A., OZHMEGOV, K. Experimental studies on Zr-1\%Nb alloy properties in technological conditions of cold pilger tube rolling proces. Archives of Civil and Mechanical Engineering. 2019, vol, 19, no. 1, pp. 268-273.

[18] SKRIPALENKO, M.M., ROMANTSEV, B.A., GALKIN, S.P., KAPUTKINA, L.M., SKRIPALENKO, M.N. Study of Strain and Structural Peculiarities in Different Stages of Two- and Three-High Screw Rolling. Steel in Translation. 2019, vol. 49, no. 10, pp. 709-715.

[19] GALKIN, S.P. Radial shear rolling as an optimal technology for lean production. Steel in Translation. 2014, vol. 44, no, 1, pp. 61-64.

[20] DEREVYAGINA, L.S., GORDIENKO, A.I., POCHIVALOV, Y.I., SMIRNOVA, A.S. Modification of the Structure of Low-Carbon Pipe Steel by Helical Rolling, and the Increase in Its Strength and Cold Resistance. Physics of Metals and Metallography. 2018, vol. 119, no. 1, pp. 83-91.

[21] ALESHCHENKO, A.S., BUDNIKOV, A.S., KHARITONOV, E.A. Metal Forming Study during Pipe Reduction on Three-High Rolling Mills. Steel in Translation. 2019, vol. 49, no. 10, pp. 661-666.

[22] NAIZABEKOV, A.B., LEZHNEV, S.N., DYJA, H., BAJOR, T., TSAY, K., ARBUZ, A., GUSSEYNOV, N., NEMKAEVA, R. The effect of cross rolling on the microstructure of ferrous and non-ferrous metals and alloys. Metalurgija. 2017, vol. 56, no. 1-2, pp. 199-202.

[23] NAIZABEKOV, A., LEZHNEV, S., ARBUZ, A., PANIN, E., VOLOKITINA, I. The development and testing of a new method of qualitative analysis of the microstructure quality, for example of steel AISI 321 subjected to radial shear rolling. Physica Scripta. 2019, vol. 94, no. 10, article number 105702.

[24] BAJOR, T., KULAKOWSKA, A., DYJA, H. Analysis of the rolling process of alloy 6005 in a three-high skew rolling mill. Materials. 2020, vol. 13, no. 5, article number 1114.

[25] AKOPYAN, T.K., GAMIN, Y.V., GALKIN, S.P., PROSVIRYAKOV, A.S., ALESHCHENKO, A.S., NOSHIN, M.A., KOSHMIN, A.N., FOMIN, A.V., Radial-shear rolling of high-strength aluminum alloys: Finite element simulation and analysis of microstructure and mechanical properties. Materials Science and Engineering: A. 2020, vol. 786, no. 139424.

[26] DIEZ, M., KIM, H.-E., SEREBRYANY, V., DOBATKIN, S., ESTRIN, Y. Improving the mechanical properties of pure magnesium by three-roll planetary milling. Materials Science and Engineering: A. 2014, vol. 612, pp. 287292.

[27] KAWAŁEK, A., DYJA, H., GALKIN, A.M., OZHMEGOV, K.V., KNAPIŃSKI, M. Physical modelling of the plastic working processes of modified Zr-Nb zirconium alloy bars and tubes. Metalurgija. 2015, vol. 54, no. 1, pp.79-82. 